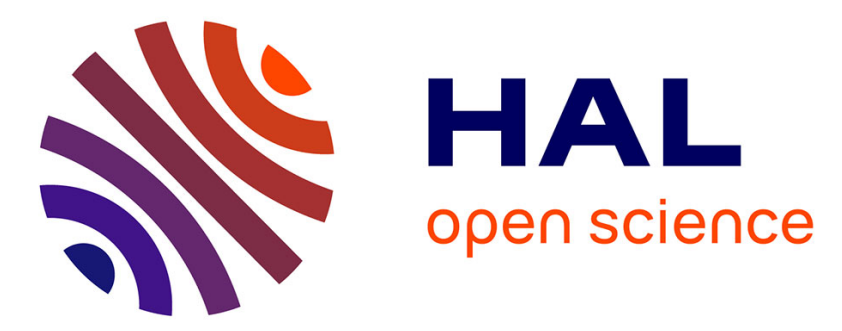

\title{
STUDIES ON THE MAGNETISM AT THE SURFACE AND INTERFACE USING POLARISED NEUTRONS
}

\author{
Y. Endoh
}

\section{To cite this version:}

Y. Endoh. STUDIES ON THE MAGNETISM AT THE SURFACE AND INTERFACE USING POLARISED NEUTRONS. Journal de Physique Colloques, 1982, 43 (C7), pp.C7-159-C7-166. 10.1051/jphyscol:1982724 . jpa-00222331

\section{HAL Id: jpa-00222331 https://hal.science/jpa-00222331}

Submitted on 1 Jan 1982

HAL is a multi-disciplinary open access archive for the deposit and dissemination of scientific research documents, whether they are published or not. The documents may come from teaching and research institutions in France or abroad, or from public or private research centers.
L'archive ouverte pluridisciplinaire HAL, est destinée au dépôt et à la diffusion de documents scientifiques de niveau recherche, publiés ou non, émanant des établissements d'enseignement et de recherche français ou étrangers, des laboratoires publics ou privés. 
JOURNAL DE PHYSIQUE

ColZoque C7, supplément au n¹2, Tome 43, décembre 1982

page $\mathrm{C} 7-159$

\title{
STUDIES ON THE MAGNETISM AT THE SURFACE AND INTERFACE USING POLARISED NEUTRONS
}

Y. Endoh

Department of Physics, Tohoku University, Sendai 980, Japan

Résumé.- Les études rêcentes par diffraction neutronique de l'effet de surface sur le ferromagnétisme sont présentées. Les nouvelles propriêtés physiques observées dans les films à surstructure artificielle ont attiré tant les théoriciens que les expérimentateurs. L'étude magnétique de ces films par neutrons polarisés est l'objet principal de ce papier. De plus, plusieurs applications des neutrons polarisés pour l'étude de l'effet de surface sont présentées.

\begin{abstract}
Recent neutron diffraction studies of the effect of the surface on ferromagnetism are reviewed. Novel Physical properties in artificial superstructure films have attracted both theoretical and experimental interests and therefore the magnetic studies from such films using polarised neutrons are discussed mainly in this paper. In addition, several applications of polarized neutrons for studies of surface effects are presented.
\end{abstract}

1. INTRODUCTION.

The present paper reviews recent neutron scattering studies on the effect of surfaces and/or interfaces on fexromagnetism. Since thermal neutrons penetrate deeply inside most materials, neutron scattering may not be the best tool for the studies exploring surface phenomena. However magnetic studies using neutrons, in particular polarized neutrons can afford us direct knowledge of how the magnetic moment behaves both in space and time. Therefore if one overcomes experimental difficulties not only of above mentioned disadvantage but also of weak scattering intensity compared with that of the photon scattering, polarized neutrons are believed to be still a very powerful probe for the study of surface magnetism.

Most recently the change of bulk properties in so called artificial superstructure films (ASF) have attracted much attention. The modifications of the physical properties, particularly the magnetic properties near the surface overlayered with other non-magnetic materials are so substantial that novel physical features are expected to appear /I/ and actually are realized. The ASF also known as compositionally modulated films, consists of regularly or coherently stacked bilayers of (A-B) type, where $A$ is ferromagnetic and $B$ is non-magnetic for instance, which eventually gives rise to the regular stratified structure. At each interface of ferromagnetic layers of $A$ there exists a surface effect varying with contacting overlayered element of $B$. Applying simple kinematical theory of neutron diffraction to the study of such ASF we could present the observation of the spatial magnetic density distribution within the magnetic layers $/ 2 /$. If one uses 
an ASF consisting of enough bilayers to measure by the standard neutron diffraction method, one can detect the magnetization distribution which theoretists find as the results of their model calculations. Fortunately the current techniques of ultra high vacuum deposition provide us such ASF of the high quality necessary for neutron diffraction studies.

Since we have already described the principles and essentiatl problems facing the experiments $/ 2-4 /$, we just summarize the recent results of neutron diffraction experiments. We will briefly discuss the significance of polarized neutron studies on this particular problem. We will also present other applications of polarized neutron experiments to the surface magnetism using ultra fine particles $/ 5,6 /$ and flat metal surface of magnetic materials $/ 7 /$.

\section{POLARIZED NEUTRON DIFFRACTION FROM ASF}

Materials of such ASF have been produced in several places mostly by means of ultra high vacuum deposition. The thickness of bilayers is in the range of several $\mathrm{nm}$ to $10 \mathrm{~nm}$, and the number of bilayers, $n$, is from $\sim 100$ to $\sim 1000$. In order to produce a sample with uniform and sharp interface boundaries, the evaporating rate is controlled to be constant and substrates are sometimes cooled preventing interdiffusion at the interface. In our case, the typical evaporation rate is $\sim 0.02$ $\mathrm{nm} / \mathrm{sec}$ in a $10^{-9}$ Torr atmosphere and the deposition temperature is $200 \sim 250 \mathrm{~K}$.

Polarized neutron studies on such films are currently performed by several groups in both United States /8/ and Japan /2,3,4/ independent1Y. Magnetic studies(magnetization and susceptibility measurements, ESR, Mossbauer spectroscopy, other than neutron diffraction)are carried out in many places. Although the research activities on this subject are still growing rapidly and some results are controversial, we attempt to summarize magnetic properties near the interface of magnetic layers in such films in Table 1.

Table 1 - Magnetic Properties near the interface of ASF. M, MS, ND, ESR in the column of experiment represent respectively Magnetization, Mössbauer Spectroscopy Neutron Diffraction and Electron Spin Resonance.

Materials\&Typical structure

\begin{tabular}{|c|c|}
\hline $\begin{array}{l}\mathrm{Fe} \cdot \mathrm{MgF}_{2} \\
\mathrm{Fe} \cdot \mathrm{MgO}^{2}\end{array}$ & $\mathrm{~A}_{100} \mathrm{~B}_{160}$ \\
\hline $\begin{array}{l}\text { Fe.SiO } \\
\text { Se.Sb }\end{array}$ & $\begin{array}{l}\left(A_{20} 0_{40}\right) \times 80 \\
\left(A_{x} B_{y}\right) \times 100 \\
2<x<30,40<y<60\end{array}$ \\
\hline FePd & $\begin{array}{l}\left(A_{21} B_{62}\right) \times 50 \\
\left(A_{5} B_{10}\right) \times n\end{array}$ \\
\hline $\mathrm{FeNi}-\mathrm{Cu}$ & $\left(\mathrm{A}_{10} \mathrm{~B}_{100}\right) \times \mathrm{n}$ \\
\hline FeNi-Ag & \\
\hline $\mathrm{FeV}$ & 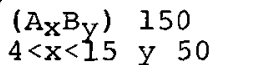 \\
\hline $\mathrm{NiCu}$ & $\left(\mathrm{A}_{10} \mathrm{~B}_{20}\right) \times 880$ \\
\hline & $\begin{array}{l}\left(\mathrm{A}_{88} \mathrm{~B}^{\mathrm{B}} 13,2\right) \times 800 \\
\left(\mathrm{~A}_{20} \mathrm{~B}_{40}\right)^{2} \times 200\end{array}$ \\
\hline$i$ & \\
\hline
\end{tabular}

\section{Interface Magnetic Properties}

$\begin{array}{lll}\begin{array}{l}\text { Magnetisation (M) } \\ \text { slightly enhanced }\end{array} & \text { MS } & / 9,10 / \\ \text { MS } & / 9,10 / \\ \text { M.dead } & \text { ND } & / 2 / \\ \text { M.enhanced o K } & \text { MS\&ND } & / 11,12 / \\ \begin{array}{l}\text { M.increase } \\ \text { TC decrease }\end{array} & \text { MS\&ND } & / 13,3 / \\ \text { M slightly decrease } & \text { M,ESR } & / 14 / \\ \text { M.decrease } & & / 15 / \\ \begin{array}{l}\text { M.decrease } \\ \text { unusual anisotropy }\end{array} & \text { MS,ND } & / 17 / \\ \text { M.enhance } & \text { M,ESR } & / 18,19 / \\ \begin{array}{l}\text { M.dead } \\ \text { M.dead }\end{array} & \text { ND } & / 8 / \\ & \text { ND } & / 2 / \\ & \text { ND } & / 20 /\end{array}$

As described in the preceding section, the ASF is ideally made up of perfect repetition of bilayers consisting of $A$ and $B$ atomic layers. The structure gives rise to Bragg reflections at scattering positions 
corresponding to the basic period in $\mathrm{x}$ ray or neutron diffraction. The peak intensity is easily calculated by the kinematical theory of diffraction which has been described in previous papers. $/ 2,4 /$ Note that the structure factor in the diffraction patterns from such films has also been given by Felcher et al. /8/. They introduced the atomic displacement from the average position as well as the concentration fluctuation, which gives rise to a more versatile form than our treatment.

Using polarized neutrons the flipping ratios of the scattering intensity for neutrons polarized parallel and antiparallel to the magnetization yield the spatial modulation of magnetization along the direction normal to the film plane. The measurements are very similar to the magnetic form factor observation, but the present subject is directed to the density distribution on a more macroscopic scale in real space. The essential results obtained by polarized neutron diffraction are as follows. Firstly the modulation in magnetization is given with respect to the satellite order. Therefore if the magnetization is assumed to be uniform throughout magnetic layers, the flipping ratios should be independent of the order of satellite reflections. Therefore if we observe different flipping ratios with respect to the satellite order, we expect the modulation of magnetization density possibly due to the effect of interfaces. Secondly the flipping ratio is essentially independent of structural defect; the result is independent of the interface quality (either uniform or irregular). Therefore in this respect the present method has a great advantage, while on the other hand the interface quality seems to be a difficulty in other microscopic spectropies or the measurements of bulk properties. Finally the present method yields model independent results of the spatial distribution of magnetic density in the films, since the observed quantities are the Fourier transformation of the spatial distribution itself.

In principle therefore polarized neutron diffraction studies can afford clear evidence of the interfacial effect by observing the spatial distribution of the magnetic density in the ASF. However we face the difficult problems of the extinction correction./2,4/ Since the width of the Bragg angle distribution of the superlattice reflection of the artificial bilayer periodicity is narrow $\left(\theta_{B} \cdot(\Delta d / d), \theta_{B}\right.$, Bragg angle, $d$, spacing of the bilayer, respectively), the beams reflected by the successive layers are mostly coherent. Therefore the ASF can be regarded as an 'ideal' crystal, which eventually leads the primary extinction to be dominant. Although the primary extinciton correction should be treated on the basis of the optical theory to analyse the wave equation of the neutrons, /21/ the conventionaly approximation was also found to be very useful. /2/ The integrated intensity $\mathrm{R}$ can be given as

$$
R \sim q Q \tanh (n q)
$$

- where $q, n$ are respectively the scattering power, and number of bilayers. Since $q$ is proportional to the neutron wave length $\lambda, R$ deviateds from the linear relationship of $q$ with increasing $\lambda$ and $n$. This means that either the $\lambda$ or $n$-dependence of the diffraction constitutes a reliable method of estimating the extinction effect. We carried out such experiments and found that the flipping ratio of the lst satellite changes with $\lambda$ or $\mathrm{n}$. An example is shown in fig. 1. /2,4/ Let us look at the neutron diffraction results. Although examples are Iimited in numbers as is seen in Table 1 , several significant features can be proposed. The magnetic moment of Fe near the interface was found to vary with contacting elements. Magnetic states were found not to be substnatially modified in $\mathrm{Fe} / \mathrm{SiO}$ films. Instead the hyperfine field in similar films of $\mathrm{Fe} / \mathrm{MgF}_{2}$ and $\mathrm{Fe} / \mathrm{MgO}$ is slightly enhanced by $5 \%$. On the contrary, the top layer of Fe contacting with $\mathrm{Sb}$ seems to be 
magnetically dead. It is interesting that the neutron diffraction result is consistent with the results of the Mobsauer spectroscopy; an Fe layer on the $\mathrm{Sb}$ substrate layer loses its magnetic moment. We speculated then that the inplane configuration of $\mathrm{Fe}$ atoms in this layer may be modulated from that of b.c.c.Fe.

The driving force of the change in the magnetic properties in the $\mathrm{Fe} / \mathrm{Sb}$ interface is presumably attributed to the change in the atomic configuration of interface $F e$ layers. The change in the magnetic state of $\mathrm{Fe}$ near the interface in $\mathrm{Fe} / \mathrm{Pd} \mathrm{ASF}$ is more dramatic. At lower temperature the magnetization near the interface rather increases, while on the other hand it diminishes rapidly upon heating to become non ferromagnetic at room temperature. The experiments have not yet been completed, but this temperature evolution is remarkably interesting. We illustrate in Fig.2 the proposed magnetization density distribution of both $\mathrm{Fe} / \mathrm{Sb}$ and $\mathrm{Fe} / \mathrm{Pd} \mathrm{ASF}$ at $4.2 \mathrm{~K} .14 / \mathrm{Com}-$ pared with Fe interface, the theoretical effort has been inclined toward the problem of the interface and surface effects on the ferromagnetism in $\mathrm{Ni}$. However the experiments of neutron diffraction have not been done until very recently. All the results reported here show the reduction in the magnetization of $\mathrm{Ni}$ near the interface, no matter what the contacting materials are.

To conclude this section, we have demonstrated that polarized neutron diffraction is useful in the study of interface magnetism. In order to compare with the results of the recent electron band theory /1/ we must accumulate more data from systematic studies on different materials.

\section{NOVEL FEATURE OF ARTIFICIAL MAGNETIC FILMS}

As many theories predicted, the magnetic properties as well as other physical feature are strongly dependent on the detailed environment of many transition metals. Since the density of states of d electron bands is expected to change by breaking the symmetry at the surface, the magnetic properties may also be modified significantly $/ 1 /$. Experimentally these ASF were found to become epitaxial sandwich films when the crystal orientation is alligned. Brodsky et al. have suceeded in growing such sandwich films and have found novel features. $122,23 /$ For instance they made $\mathrm{Au}-\mathrm{Cr}-\mathrm{Au}$ sandwich films depositing $\mathrm{Cr}$ on the Au (III) or (100) layers. Then $\mathrm{Cr}$ grows as the face centered 
cubic structure and becomes a superconductor due probably to the high electron density of states at the Fermi energy. Another example is the Ag-Pd-Ag sandwich films in which Pd was grown on Ag(100) with stretching of the lattice at the interface. It seems to be equivalent to applying negative pressure. /24/ They found a tremendous increase of the susceptibility at lower temperatures due to the fact that the narrowing of the band resulted in an increase of electron density of states at the Fermi energy. As summarized in Table II, there exist other interesting experimental results which show the ASF as a possibly novel class of material, such as high temperature superconductor, new magnetic substance and so forth. Thus the research of ASF will continue to be a rich field in not only the academic science but also the applied material science.

4. POLARIZED NEUTRON SCATTERING OF MAGNETIC FINE PARTICLES AND MAGNETIC METAL SURFACES

The surface magnetization measurements of ferromagnetic fine particles using polarized neutrons have been carried out by
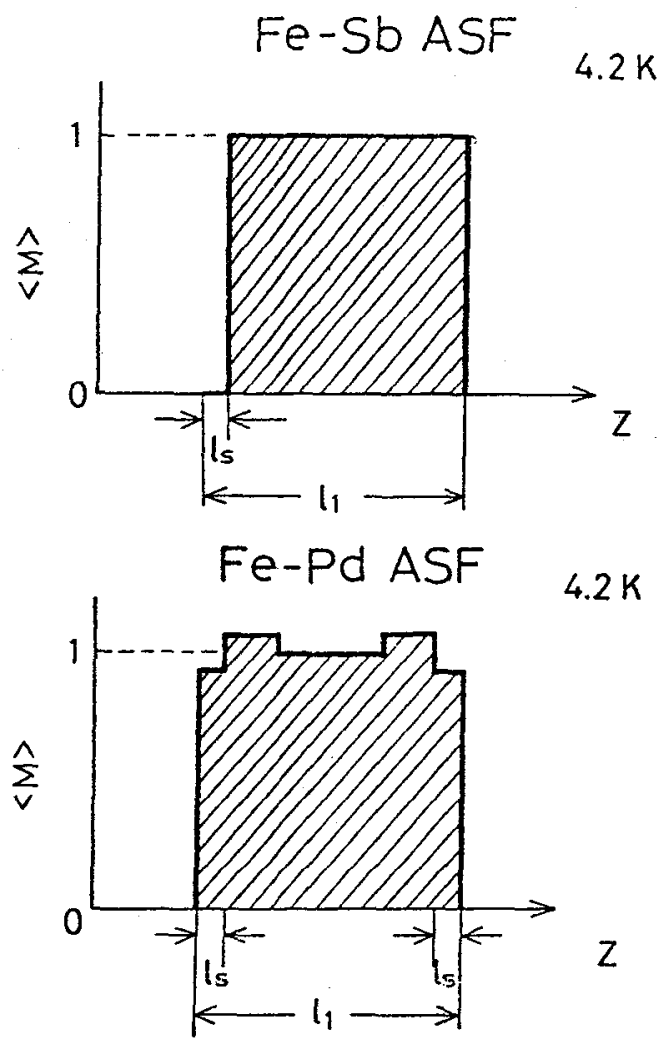

Fig.2 Schematic drawing of spatial distributions of the $\mathrm{Fe}$ magnetization density in $\mathrm{Fe} / \mathrm{Sb}$, and $\mathrm{Fe} / \mathrm{Pd}$ $\mathrm{ASF}$ at $4.2 \mathrm{~K}$.

Table II - Physical properties in Epitaxial Growing Sandwich Films. $X$ and $\rho$ in the fourth colunm are susceptibility and resitibity measurements. Other symbols are the same as in table I.

Materials\&Structure Physical Properties Experiments

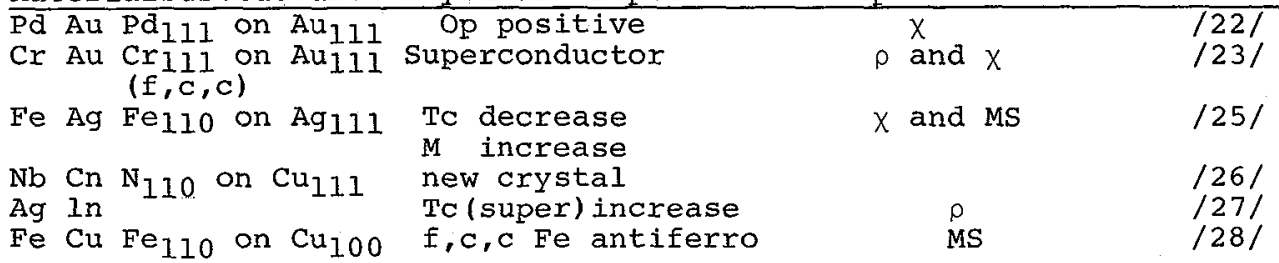

Sato and Hirakawa for the first time in 1975. /5/ Ignoring the fine structure inside the particles or regarding them as a uniform scattering medium, the neutron scattering amplitude for assemblies of small spheres is given by

$$
\begin{aligned}
& f(k)=4 N b r^{3} g(\kappa r), \\
& g(x)=\frac{\sin x}{x^{3}}-\frac{\cos x}{x^{2}}
\end{aligned}
$$


Where $k, b, r$ are respectively, scattering vector, neutron coherent scattering amplitude and the mean radius of particles. Based on the same arguement described previously, the small angle polarized neutron scattering can detect the anomalies in the surface magnetization observing the $k$ dependence of the flipping ratio. When the surface magnetization is either reduced or reversed in comparison with the bulk magnetization, the flipping ratios oscillate with respect to $k$, which is schematically drawn in Fig.3 together with the result of recent observations from $\mathrm{Ni}$ fine particles./6/

The advantage of using polarized neutrons is again the fact that the flipping ratio is independent of the scattering contrast which is often observed in small angle scattering from liquids as the effect of density-density correlations. Furthermore, the TOF method using pulsed polarized neutrons is feasible for such diffuse scattering observable in a wide range of the momentum space $Q$. In this example we found anomalous surface layers of either magnetically 'dead' or 'reversed' layers, which was originally found by Sato and Hirakawa. However the Ni particles are always covered by Nio which prevents us from definitive conclusion about the surface magnetism.

The last example to elucidate the surface magnetism using polarized neutrons is the reflection of polarized neutrons from magnetic flat surfaces. /7/ Applying the spin dependent refractive index of neutrons, the magnetization near the surface can be detectable. Namely

$$
\begin{aligned}
& \mathrm{n}_{ \pm}=\mathrm{n}_{N} \pm \mathrm{n}_{\mathrm{M}}=1-\frac{\lambda^{2}}{2 \pi} \cdot \frac{1}{\mathrm{~V}}(\mathrm{~b} \pm \mathrm{p}),( \\
& \mathrm{R}_{ \pm}=\left|\frac{\sin \theta_{0}-\left(\mathrm{n}^{2}{ }_{ \pm}-\cos ^{2} \theta_{0}\right)^{1 / 2}}{\sin \theta_{0}+\left(\mathrm{n}^{2}{ }_{ \pm}-\cos ^{2} \theta_{0}\right)^{-/ 2}}\right|^{2},
\end{aligned}
$$

where $n_{ \pm}, R_{ \pm}$are the refractive index and reflectivity of the surface material. $\theta_{0}$ is the glancing angle of the incident beam with the surface. If $\theta_{0}$ is smaller than a critical angle $\theta_{c}$, the reflectivity is unitary. However the reflectivity drops rapidly with increasing $\theta_{0}$ above $\theta_{c}$. Since $n \pm$ depends on the coheren magnetic scattering amplitude $p$, the flipping ratio of the reflected neutrons at angles close to $\theta$ is extremely sensitive to the magnnetic state near the surface. The accuracy may not be clear because the surface effect is localized in a surface

layer or at least a few atomic layers from the very top, while neutrons deeply penetrate inside materials. It seems to be promising 
the surface effect near $T$, where the surface effect also penetrates inside as the exponential form of power law in $(\mathrm{T}-\mathrm{T})$. Then it becomes comparable order to the depth of neutron penetration.

\section{CONCLUSION}

The surface physics itself is very interesting since the symmetry breaking causes many important effects : When we are confined in the field of magnetism, the effect of surface and/or interface on magnetism can be expected to be so rich and varied that the surface becomes ferromagnetic from the nonmagnetic in the bulk material in one extreme case and vice versa in other cases. This means that it is very important to make a clear experiment to extract indispensable information about the surface effect. We emphasize again that polarized neutrons have a potential, because the results are rather straightforwardly related to the spatial distributions of magnetization density near surfaces and interfaces. As demonstrated in the present paper the results are mostly free from any disturbance of structural problems without using any specific model to extract magnetization.

We hope that this presentation will stimulate further important polarized neutron work on the research field of interface magnetism.

The author thanks M.B.Brodsky and G.P.Felcher for many interesting conversations: He is indebted to T.Shinjo, N.Hosoito, S.Ikeda, H.Ono, S.Mitsuda and M.Sato for their close collaborations on this matter. He wishes to thank Yamada Science Foundation for the part of financial support of his travel.

References

7 I/ FREEMAN A.J., XU J, and JARLBORG T., Proc. Int. Conf. Mag. (Kyoto, Japan Sept. 6-10, 1982) to appear in J.Mag.Mag.Mat.

/2/ SATO M., ABE K., ENDOH Y., and HAYTER J., J.Phys. C 13 (1980) 3563

/3/ ONO H., ENDOH Y., HOSOITO N., SHINJO T., and IKEDA S., KEK Internal 82-5, (1982) 90

/4/ ENDOH Y., HOSOTTO N. and SHINJO T., Proc. 10th Int. Col. Mag.Films Surf. (Yokohama, Japan Sept 13-16,1982) to appear in J.Mag. Mag. Mat.

/5/ SATO M. and HIRAKAWA K., J.phys.Soc.Jpn 39 (1975) 1467

/6/ IKEDA S., and ENDOH Y., KEK. Internal 82-5, (1982) 96

/7/ FELCHER G.P., Phys. Rev. B 24 (1981) 1595

/8/ FELCHER G.P., CABLE J.W., ZHENG J.Q., KETTERSON J.B. and HILLIARD J,E., J.Mag.Mag.Mat. 21 (1980)L198

/9/ SHINJO T., HINE S. and TAKADA T., Proc 7 th Int. Vac. Congr. (Vienna, 1977) 2655

$/ 10 /$ HINE S., SHINJO T. and TAKADA T., J.Phys.Soc.Jpn 47 (1979) 767

/I1/ HOSOITO N., KAWAGUCHI $k_{\text {. }}$, SHINJO T. and TAKADA T., J.Phys.SOC. Jpn 51 (1982)

$112 /$ ENDOF Y., ONO H., HOSOITO N. and SHINJO T., PrOc. Int.Conf. Mag. (Kyoto, Japan Sept 6-10, 1982) to appear in J.Mag.Mag.Mat.

113/ HOSOITO N., SHINJO T. and TAKADA T., J.Phys.SOC.Jpn 50 (1981) 1903

/14/ DUBLON G., ROSENBLUM M.P. and VETTERLING W.T., IEEE Erans. Mag. $16(1980) 1126$

/15/ SMIT J.W., J.VAC.SCI.Tech. 19 (1981) 704

/16/ GRADMANN V., J.Mag.Mag.Mat $\overline{6}$ (1977) 173

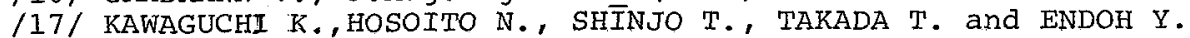
unpublished

/18/ GYORGY E.M., DILLON JY.J.R., MCWHAN D.B., RUPP Jr.I.W., TESTARDI L.R. and FLANDERS P.J., PHYS.Rev.Lett. $\underline{45}$ (1980) 57 
/19/ DILLON Jr.J.F., GYORGY E.M., RUPP Jr.L.W., YAFET Y. and TESTARDI L.R., J. appl. Phys. 52 (1981) 2256

/20/ FELCHER G.P. , private communications.

/21/ JAMES R.W. 1962 The Optical Principles of Diffraction of $x$ rays (Lonđon : Bell)

$122 /$ BRODSKY M.B. and FREEMAN A.J., Phys.Rev.Lett. 45 (1980) 133

$123 /$ BRODSKY M.B. MARIKAR P., FRIDDLE R.J., SINGEK L. and SOWERS C.H., Solid State Commu. 42 (1982) 675

/24/ JARLBORG T. and FREEMAN A.J. , Physica $107 \mathrm{~B}+\mathrm{C}$ (1981) 69

$125 /$ TYSON J., OWENS A.H. and WALKER J.C., J.appl phys. 52 (1981) 2487

/26/ SCHLLER I.K., phys.Rev.Lett. 44 (1980) 1597

/27/ GRANQUIST C.G. and CLAESON T. "Solid State Commu 32 (1979) 531

$128 /$ KEUNE W., HARBAUER R., GONSER U., LAUER J.and WILIIAMSON K.L., J.Mag.Mag.Mat. 6 (1977) 192 